\title{
Acetylene Gas-Sensing Properties of Layer-by-Layer Self-Assembled Ag-Decorated Tin Dioxide/Graphene Nanocomposite Film
}

\author{
Chuanxing Jiang ${ }^{1}$, Dongzhi Zhang ${ }^{1, *} \mathbb{B}$, Nailiang Yin ${ }^{1}$, Yao Yao ${ }^{2}$, Talgar Shaymurat ${ }^{3}$ and \\ Xiaoyan Zhou ${ }^{4}$ \\ 1 College of Information and Control Engineering, China University of Petroleum (East China), \\ Qingdao 266580, China; jiangchuanxing@126.com (C.J.); nailiang_yin@163.com (N.Y.) \\ 2 College of Communication Engineering, Chengdu University of Information Technology, \\ Chengdu 610225, China; yaoyao@cuit.edu.cn \\ 3 Key Laboratory of New Energy and Materials Research, Xinjiang Institute of Engineering, \\ Urumqi 83000, China; talgar.shaymurat@vip.163.com \\ 4 College of Science, China University of Petroleum (East China), Qingdao 266580, China; \\ zhouxiaoyan@upc.edu.cn \\ * Correspondence: dzzhang@upc.edu.cn; Tel.: +86-532-86981335
}

Received: 22 August 2017; Accepted: 14 September 2017; Published: 18 September 2017

\begin{abstract}
This paper demonstrates an acetylene gas sensor based on an Ag-decorated tin dioxide/reduced graphene oxide $\left(\mathrm{Ag}-\mathrm{SnO}_{2} / \mathrm{rGO}\right)$ nanocomposite film, prepared by layer-by-layer (LbL) self-assembly technology. The as-prepared $\mathrm{Ag}-\mathrm{SnO}_{2} / \mathrm{rGO}$ nanocomposite was characterized by scanning electron microscopy (SEM), transmission electron microscopy (TEM), X-ray diffraction (XRD) and Raman spectrum. The acetylene sensing properties were investigated using different working temperatures and gas concentrations. An optimal temperature of $90{ }^{\circ} \mathrm{C}$ was determined, and the $\mathrm{Ag}-\mathrm{SnO}_{2} / \mathrm{rGO}$ nanocomposite sensor exhibited excellent sensing behaviors towards acetylene, in terms of response, repeatability, stability and response/recovery characteristics, which were superior to the pure $\mathrm{SnO}_{2}$ and $\mathrm{SnO}_{2} / \mathrm{rGO}$ film sensors. The sensing mechanism of the $\mathrm{Ag}-\mathrm{SnO}_{2} / \mathrm{rGO}$ sensor was attributed to the synergistic effect of the ternary nanomaterials, and the heterojunctions created at the interfaces between $\mathrm{SnO}_{2}$ and $\mathrm{rGO}$. This work indicates that the $\mathrm{Ag}-\mathrm{SnO}_{2} / \mathrm{rGO}$ nanocomposite is a good candidate for constructing a low-temperature acetylene sensor.
\end{abstract}

Keywords: graphene; layer-by-layer self-assembly; nanocomposite film; acetylene sensor

\section{Introduction}

Acetylene $\left(\mathrm{C}_{2} \mathrm{H}_{2}\right)$ is a colorless and highly combustible gaseous hydrocarbon, widely used as a fuel in many industrial fields, such as metal welding [1], polyacetylene preparation [2], lithium-ion batteries [3], and conductive plastic manufacturing [4]. However, acetylene is unstable and there is a huge potential risk of fire or explosive accidents during its compression and heat treatment, or due to leakage. Furthermore, the dissolved content of acetylene gas in power transformer oil is critical to the safety and reliability of the transformer system $[5,6]$. Therefore, reliable, economical and portable acetylene gas sensors are of great importance to many applications. In recent years, a lot of interest has been attracted surrounding the development of effective techniques and sensitive methods for acetylene gas detection, such as photoacoustic spectroscopy [7], optical fiber [6,8] and metal-oxide semiconductors (MOS) and nanomaterial-based sensors (i.e., PdO-decorated $\mathrm{SnO}_{2}$ [9], $\mathrm{Au} /$ multi-wall carbon nanotubes [10], $\mathrm{Sm}_{2} \mathrm{O}_{3}$-decorated $\mathrm{SnO}_{2}$ [11], Ag-loaded $\mathrm{ZnO}$ [12-14] and $\mathrm{NiO} / \mathrm{SnO}_{2}$ heterostructures [15]). Among them, metal oxides have become important candidates 
for acetylene sensing due to their unique advantages-such as their small size and simplicity of integration - but they lack selectivity towards different gas species, and often require high operating temperatures and have high power consumption [16-20].

The state-of-the-art MOS-based acetylene sensor focuses on noble metal-metal oxide nanohybrids and heterometal oxide nanostructures. Zhang et al. reported on the hydrothermal synthesis of hierarchical nanoparticle-decorated $\mathrm{ZnO}$ microdisks for acetylene gas sensing at $420{ }^{\circ} \mathrm{C}$ [21]. Tamaekong et al. synthesized $\mathrm{Pt} / \mathrm{ZnO}$ thick film, using the flame spray pyrolysis (FSP) technique, and a low detection limit for $50 \mathrm{ppm}$ acetylene gas was obtained at an operating temperature of $300{ }^{\circ} \mathrm{C}$ [22]. Chen et al. synthesized Pd-doped $\mathrm{SnO}_{2}$ nanoparticles using a hydrothermal method for detecting acetylene gas dissolved in power transformer oil, indicating a sensor response of 7.22 for $100 \mathrm{ppm}$ acetylene at $350{ }^{\circ} \mathrm{C}$ [23]. Zhou et al. fabricated a planar-type acetylene gas sensor based on $\mathrm{Sm}_{2} \mathrm{O}_{3}$-decorated $\mathrm{SnO}_{2}$ heterostructures, and showed that the optimum operating temperature of the sensor for $50 \mathrm{ppm}$ of acetylene is $260^{\circ} \mathrm{C}$ [11]. Uddin et al. developed a novel flexible acetylene gas sensor, consisting of Ag-loaded vertical ZnO nanorods, supported by a polyimide/ polytetrafluoroethylene (PI/PTFE) substrate, using a hydrothermal-radio frequency (RF) magnetron sputtering method and showed that its best sensing performance was at $200^{\circ} \mathrm{C}$ [12]. As a two-dimensional nanomaterial, graphene has attracted much attention since its discovery, because of its excellent characteristics, such as its electrical, chemical and optical properties [24,25]. Graphene-based nanocomposites have been widely used in membrane science and technology [26,27]. Uddin et al. synthesized a $\mathrm{ZnO} /$ reduced graphene oxide (rGO) composite using a solvothermal method, which exhibited preferential detection of acetylene gas with good selectivity, long-term stability, and fast response/recovery times at $250{ }^{\circ} \mathrm{C}$ [28]. The presented progresses suggest that noble metal doping and graphene addition techniques are effective for lowering the operating temperature and improving the acetylene sensing performance of MOS-based sensors.

In this work, we fabricated a low-temperature acetylene gas sensor based on a layer-by-layer, self-assembled $\mathrm{Ag}-\mathrm{SnO}_{2} / \mathrm{rGO}$ ternary nanocomposite film, for the first time. The as-prepared nanocomposite was characterized by scanning electron microscopy (SEM), transmission electron microscopy (TEM), X-ray diffraction (XRD) and Raman spectrum, which confirmed its successful formation and rationality. The acetylene sensing properties were investigated under different working temperatures and gas concentrations. An optimal temperature of $90{ }^{\circ} \mathrm{C}$ was determined, and the $\mathrm{Ag}-\mathrm{SnO}_{2} / \mathrm{rGO}$ nanocomposite sensor exhibited excellent sensing behaviors towards acetylene in terms of response, repeatability, stability and response/recovery characteristics. The underlying sensing mechanism of the $\mathrm{Ag}-\mathrm{SnO}_{2} / \mathrm{rGO}$ sensor was further discussed.

\section{Materials and Methods}

\subsection{Materials}

The high-purity graphene oxide (GO) nanosheets (>99\%) were supplied by Chengdu Organic Chemicals Co. Ltd. (Chengdu, China). The GO used was graphene nanosheet, negatively decorated with oxygen functional groups and carboxylic groups, which were located at the sheet surface. The GO suspension was $0.25 \mathrm{wt} \%$ concentrated at $\mathrm{pH} 4.5$. Tin chloride pentahydrate $\left(\mathrm{SnCl}_{4} \cdot 5 \mathrm{H}_{2} \mathrm{O}\right)$ and hydrazine hydrate were obtained from Sinopharm Chemical Reagent Co. Ltd. (Shanghai, China). Polyelectrolytes used for layer-by-layer (LbL) assembly were $1.5 \mathrm{wt} \%$ poly(diallyldimethylammonium chloride) [PDDA (Sigma-Aldrich Co., Saint Louis, MO, USA), molecular weights (MW) of 200-350 K] and $0.3 \mathrm{wt} \%$ poly(sodium 4-styrenesulfonate) [PSS (Sigma-Aldrich Co., Saint Louis, MO, USA), MW of $70 \mathrm{~K}$ ] with $0.5 \mathrm{M} \mathrm{NaCl}$ (West Long Chemical Co., Ltd., Guangdong, China) in both, to provide better surface coverage. All reagents were used without further purification. 


\subsection{Preparation of the $\mathrm{Ag}-\mathrm{SnO} \mathrm{O}_{2} / \mathrm{rGO}$ Nanocomposite}

Figure 1a illustrates the hydrothermal synthesis of $\mathrm{SnO}_{2}$. Firstly, $24 \mathrm{mg}$ of $\mathrm{SnCl}_{4} \cdot 5 \mathrm{H}_{2} \mathrm{O}$ was dissolved in $30 \mathrm{~mL}$ of deionized water and stirred for $1 \mathrm{~h}$. After that, the solution was hydrothermally treated at $120{ }^{\circ} \mathrm{C}$ for $12 \mathrm{~h}$, and then washed with deionized water and ethanol several times. The $\mathrm{SnO}_{2}$ aqueous solution was obtained after being ultrasonicated for $1 \mathrm{~h}$ and centrifugated for $15 \mathrm{~min}$. A substrate with interdigitated electrodes for resistive sensing and heating elements was fabricated. The $\mathrm{Ag}-\mathrm{SnO}_{2} / \mathrm{rGO}$ nanocomposite was deposited on the sensing electrodes using the layer-by-layer (LbL) self-assembly technique, which is shown in Figure 1b. Two bi-layers of PDDA/PSS were firstly self-assembled as the precursor layer, followed by alternative immersion into $\mathrm{SnO}_{2}, \mathrm{GO}, \mathrm{SnO}_{2}$ and Ag suspensions. The immersing time here used was $10 \mathrm{~min}$ for the polyelectrolytes and $15 \mathrm{~min}$ for the $\mathrm{SnO}_{2}$, GO and $\mathrm{Ag}$ suspensions. Intermediate rinsing with deionized water and drying with nitrogen gas were required after each monolayer assembly, to reinforce the interconnection between the layers. The film was formed due to the interaction of electrostatic forces between the positively and negatively charged nanoparticles. The first $\mathrm{SnO}_{2}$ layer (positively charged) was designed for the intermediate bonding between PSS (negatively charged) and GO (negatively charged). The Ag-SnO $2 /$ rGO nanocomposite sensor was obtained via the thermal reduction of GO into rGO at $220{ }^{\circ} \mathrm{C}$ for $5 \mathrm{~h}$ in an oven. Furthermore, the pure $\mathrm{SnO}_{2}$ and $\mathrm{SnO}_{2} / \mathrm{rGO}$ film sensor were fabricated to allow a comparison between the drop-casting and LbL self-assembly methods, respectively.

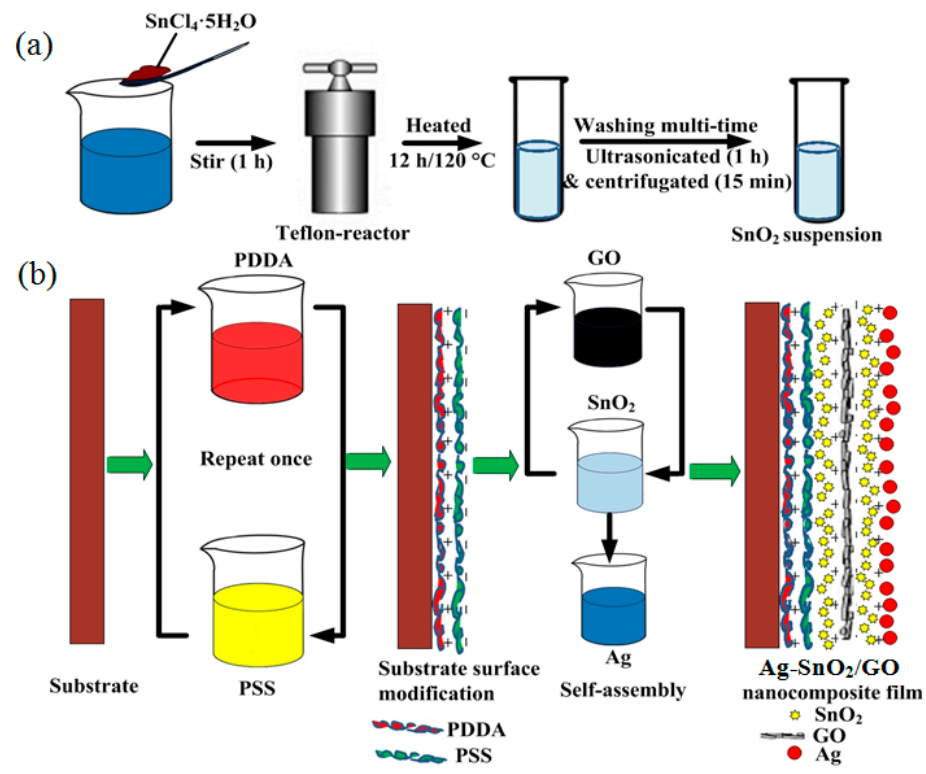

Figure 1. (a) Hydrothermal synthesis of $\mathrm{SnO}_{2}$ and (b) layer-by-layer self-assembly of the $\mathrm{Ag}-\mathrm{SnO} \mathrm{O}_{2} / \mathrm{GO}$ nanocomposite film.

\subsection{Instruments and Analysis}

Surface microscopy of the Ag-SnO $2 / \mathrm{rGO}$ sample was carried out with a scanning electron microscope (SEM, Hitachi S-4800, Tokyo, Japan). The X-ray diffraction (XRD) spectrum of the samples was examined with an X-ray diffractometer (Rigaku D/Max 2500PC, Tokyo, Japan) using Cu K $\alpha$ radiation with a wavelength of $1.5418 \AA$. The lattice fringes of $\mathrm{Ag}-\mathrm{SnO} \mathrm{O}_{2} / \mathrm{rGO}$ were inspected with a transmission electron microscope (FEI Tecnai G2 F20, Shanghai, China). The nanostructural and compositional features of the $\mathrm{Ag}-\mathrm{SnO}_{2} / \mathrm{rGO}$ and $\mathrm{SnO}_{2} / \mathrm{rGO}$ samples were characterized by Raman spectra (RamLab-010, Horiba Jobin Yvon, Paris, France).

A schematic of the experimental setup for acetylene sensing is shown in Figure 2. The acetylene gas sensing properties were investigated by exposing the sensor to various concentrations of acetylene gas, and the desired gas concentration was obtained by injecting the required quantity of acetylene 
into a sealed chamber using a syringe. The working temperature for the sensor was adjusted through applying varying voltages to the heating electrodes with a power source (Gwinstek GPD-4303S, New Taipei, Taiwan). The heater resistor $\left(R_{\mathrm{H}}\right)$, heating voltage $\left(V_{\mathrm{H}}\right)$, sensor resistance $\left(R_{\mathrm{S}}\right)$ and protection resistor $\left(R_{\mathrm{L}}\right)$ made up the simplified circuit. The sensor resistance was recorded using a data logger (Agilent 34970A, San Jose, CA, USA), connected to a computer via a recommended standard (RS)-232 interface. The sensitivity of the sensor was defined as $S=\left(R_{0}-R_{\mathrm{g}}\right) / R_{0} \times 100 \%$, where $R_{0}$ and $R_{\mathrm{g}}$ were the sensor resistances in dry air and acetylene gas, respectively. The time taken by a sensor to achieve $90 \%$ of the total resistance change was defined as the response or recovery time.

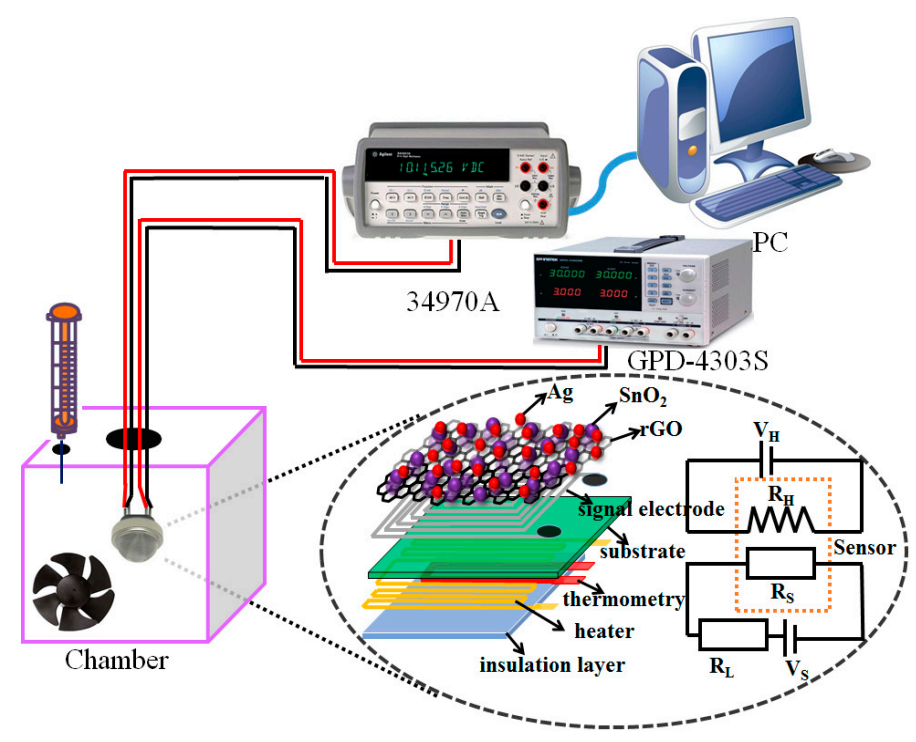

Figure 2. Schematic of the acetylene sensing experimental setup.

\section{Results and Discussion}

\subsection{Sample Characterization}

Figure 3 a shows the SEM image of the $\mathrm{Ag}-\mathrm{SnO} \mathrm{O}_{2} / \mathrm{rGO}$ nanocomposite film. $\mathrm{SnO}_{2}$ microspheres and Ag nanoparticles (NPs) attached to the surface of rGO sheets are clearly observed. Figure $3 \mathrm{~b}$ shows a high-resolution TEM image of the $\mathrm{Ag}-\mathrm{SnO}_{2} / \mathrm{rGO}$ nanocomposite, and lattice fringe spacings of $0.35,0.33$ and $0.23 \mathrm{~nm}$ for $\mathrm{rGO}, \mathrm{SnO}_{2}$ and $\mathrm{Ag}$, respectively, are measured. Figure $3 \mathrm{c}$ indicates the XRD spectrum for the $\mathrm{GO}, \mathrm{rGO}, \mathrm{SnO}_{2}$ and $\mathrm{Ag}-\mathrm{SnO}_{2} / \mathrm{rGO}$ nanocomposite films. Obvious peaks at $2 \theta$ angles of $10.78^{\circ}$ and $24.7^{\circ}$ are observed for the GO and thermally treated $\mathrm{rGO}$, respectively, which is in agreement with previously published results, and further confirms the successful reduction of $\mathrm{GO}$ via thermal treatment [29-31]. The XRD spectrum of $\mathrm{SnO}_{2}$ indicates several peaks at $26.41^{\circ}, 33.82^{\circ}, 37.60^{\circ}$, $51.73^{\circ}$ and $65.68^{\circ}$, indexed to the (110), (101), (200), (211) and (301) planes of rutile $\mathrm{SnO}_{2}$, which is in accordance with the data from JCPDS Card no. 41-1445 [32], and confirms the successful formation of $\mathrm{SnO}_{2}$ nanocrystals. Apart from the characteristic peaks attributed to $\mathrm{SnO}_{2}$, the XRD spectrum of the $\mathrm{Ag}-\mathrm{SnO}_{2} / \mathrm{rGO}$ nanocomposite exhibited distinct peaks at $38.10^{\circ}, 44.37^{\circ}$ and $64.17^{\circ}$, which indexed to the (111), (200) and (220) planes of Ag crystallines, respectively [33]. However, the broad peak of rGO is not obvious in the XRD pattern of the $\mathrm{Ag}-\mathrm{SnO}_{2} / \mathrm{rGO}$ nanocomposite, probably because the weak peak of rGO is swamped by the high intensity peak of the $\mathrm{SnO}_{2}$ at the $2 \theta$ angle of $26.41^{\circ}[34,35]$. Figure 3d shows the Raman spectrum of the $\mathrm{SnO}_{2} / \mathrm{rGO}$ and $\mathrm{Ag}-\mathrm{SnO}_{2} / \mathrm{rGO}$ nanocomposites. The peaks located at $633 \mathrm{~cm}^{-1}$ in the $\mathrm{SnO}_{2} / \mathrm{rGO}$ and $\mathrm{Ag}-\mathrm{SnO}_{2} / \mathrm{rGO}$ nanocomposites are typical Raman peaks of $\mathrm{SnO}_{2}$. The weak peaks located at 796 and $1588 \mathrm{~cm}^{-1}$ for the two samples are attributed to the Ag NPs. The peaks located at 1363 and $1640 \mathrm{~cm}^{-1}$ are attributed to defects and disorder in the graphite layer. 

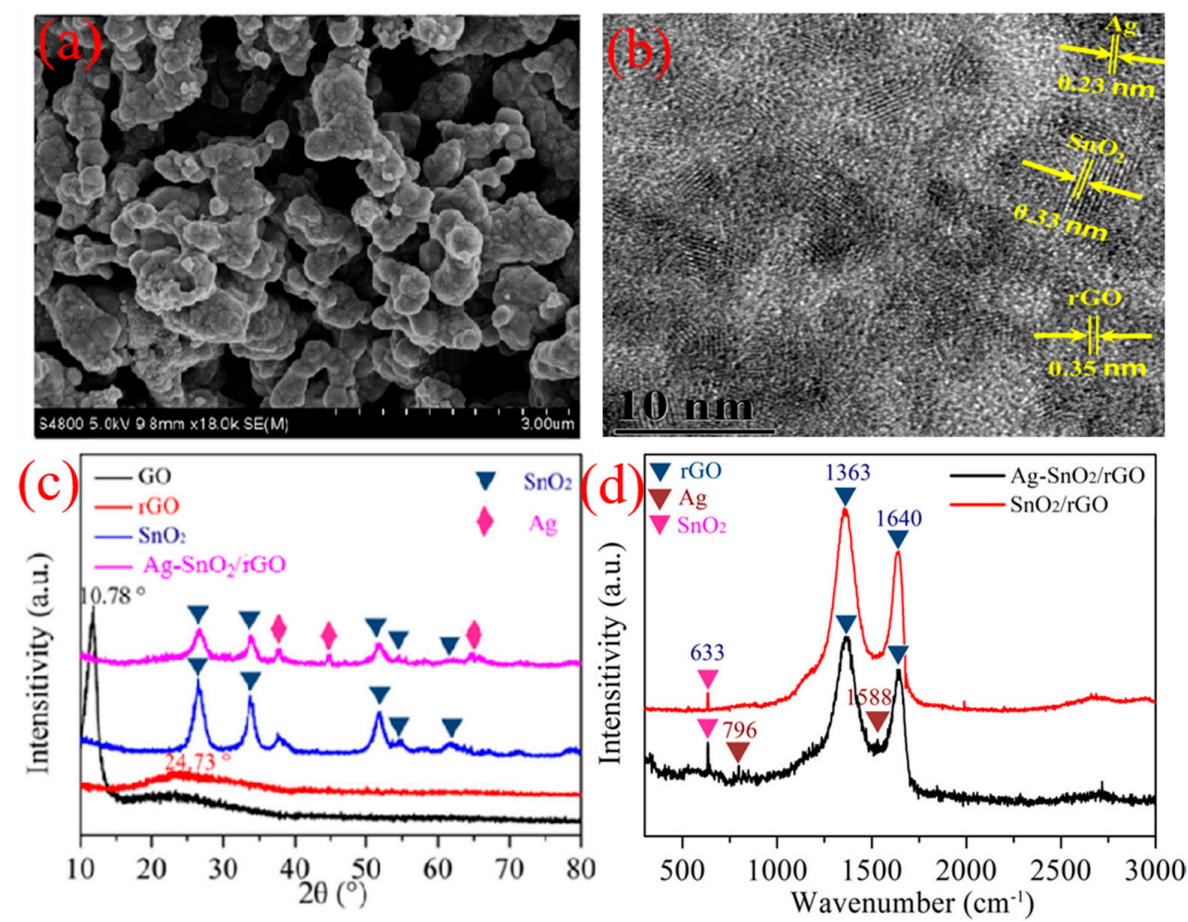

Figure 3. (a) $\mathrm{SEM}$ characterization of the $\mathrm{Ag}-\mathrm{SnO}_{2} / \mathrm{rGO}$ nanocomposite, (b) TEM image of the $\mathrm{Ag}-\mathrm{SnO}_{2} / \mathrm{rGO}$ nanocomposite, (c) XRD spectrum of $\mathrm{GO}, \mathrm{rGO}, \mathrm{SnO}_{2}$ and the $\mathrm{Ag}-\mathrm{SnO}_{2} / \mathrm{rGO}$ nanocomposite, (d) Raman spectrum of the $\mathrm{SnO}_{2} / \mathrm{rGO}$ and $\mathrm{Ag}-\mathrm{SnO}_{2} / \mathrm{rGO}$ nanocomposites.

\subsection{Acetylene Sensing Properties}

Figure 4 shows the sensitivity of the $\mathrm{Ag}-\mathrm{SnO}_{2} / \mathrm{rGO}$ nanocomposite sensor to $100 \mathrm{ppm}$ acetylene under operating temperatures of 25 to $170{ }^{\circ} \mathrm{C}$. The sensor sensitivity increases and reaches its highest value at $90^{\circ} \mathrm{C}$, and then decreases with any further increase in temperature. This can be explained by the fact that the appropriate operating temperature improves sensor sensitivity, but higher temperatures lower the binding energies of gas molecules and sensing film. An optimal temperature of $90^{\circ} \mathrm{C}$ was determined. Therefore, the operating temperature of $90^{\circ} \mathrm{C}$ was selected for the sensor in the following experiments.

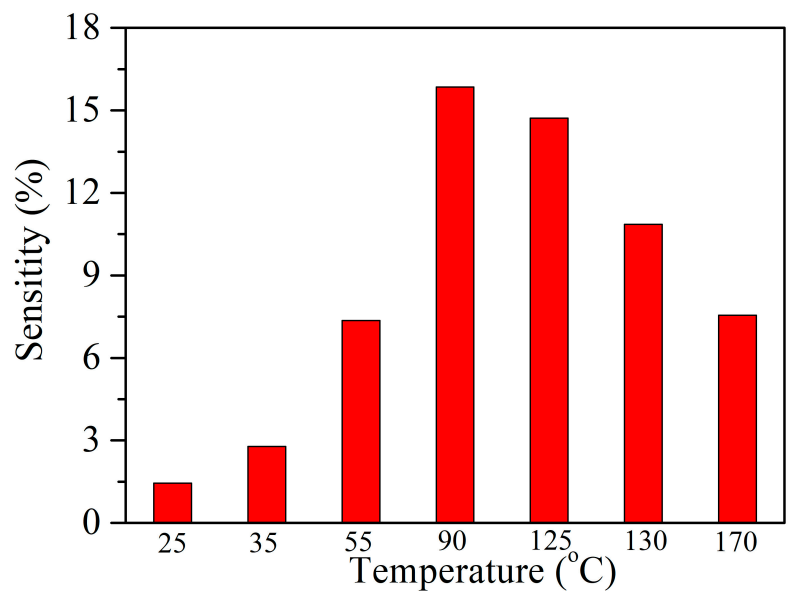

Figure 4. The sensitivity of the $\mathrm{Ag}-\mathrm{SnO}_{2} / \mathrm{rGO}$ nanocomposite sensor to $100 \mathrm{ppm}$ acetylene under different operating temperatures. 
Figure 5 shows the sensitivity of pure $\mathrm{SnO}_{2}, \mathrm{SnO}_{2} / \mathrm{rGO}$ and $\mathrm{Ag}-\mathrm{SnO}_{2} / \mathrm{rGO}$ film sensors to $50 \mathrm{ppm}$ acetylene at $90^{\circ} \mathrm{C}$. We found that the $\mathrm{Ag}-\mathrm{SnO}_{2} / \mathrm{rGO}$ film sensor yielded the highest sensitivity among the three sensors. Moreover, the $\mathrm{Ag}-\mathrm{SnO}_{2} / \mathrm{rGO}$ film sensor showed a shorter response/recovery time than the other two sensors. A response time and recovery time of 235 and $160 \mathrm{~s}$, respectively, were observed for the $\mathrm{Ag}-\mathrm{SnO}_{2} / \mathrm{rGO}$ film sensor upon exposure to $50 \mathrm{ppm}$ acetylene.

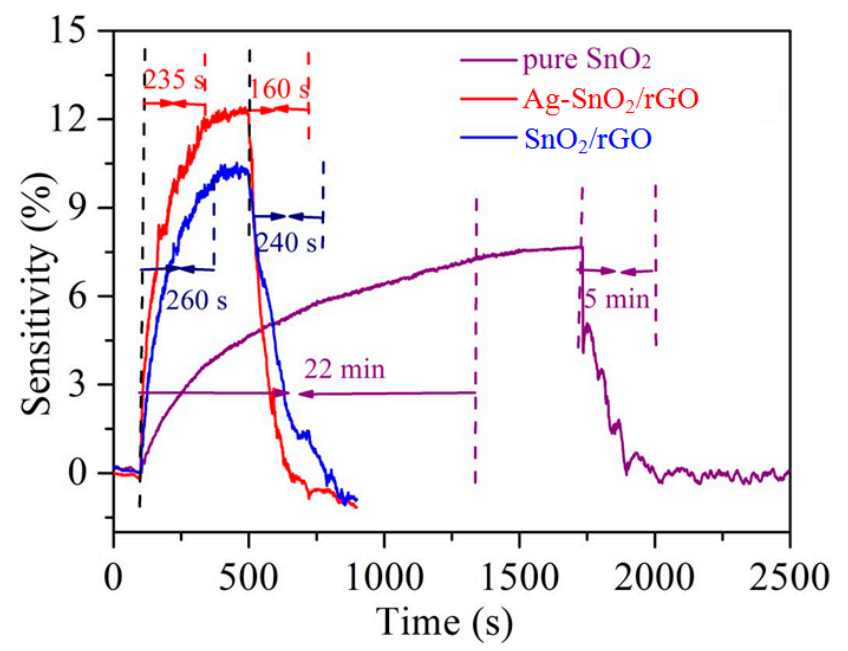

Figure 5. The sensitivity of pure $\mathrm{SnO}_{2}, \mathrm{SnO}_{2} / \mathrm{rGO}$ and $\mathrm{Ag}-\mathrm{SnO}_{2} / \mathrm{rGO}$ film sensors to $50 \mathrm{ppm}$ acetylene at $90^{\circ} \mathrm{C}$.

Figure 6 shows the resistance measurements for the $\mathrm{Ag}-\mathrm{SnO}_{2} / \mathrm{rGO}$ nanocomposite film sensor upon exposure to acetylene gas, of cumulative concentrations, at $90{ }^{\circ} \mathrm{C}$. The test was performed by exposing the sensor to 5, 10,50,100, 150 and $500 \mathrm{ppm}$ of acetylene. The resistance of the Ag-SnO $2 / \mathrm{rGO}$ nanocomposite sensor decreased with increasing concentrations of acetylene, indicating the n-type semiconductor-like behavior of $\mathrm{Ag}-\mathrm{SnO}_{2} / \mathrm{rGO}$ to acetylene (reducing gas). The inset of Figure 6 plots the fitted function of sensor sensitivity $(Y)$ and acetylene concentration $(X)$ as $Y=32.09-25.42 e^{-X / 236.4}$.

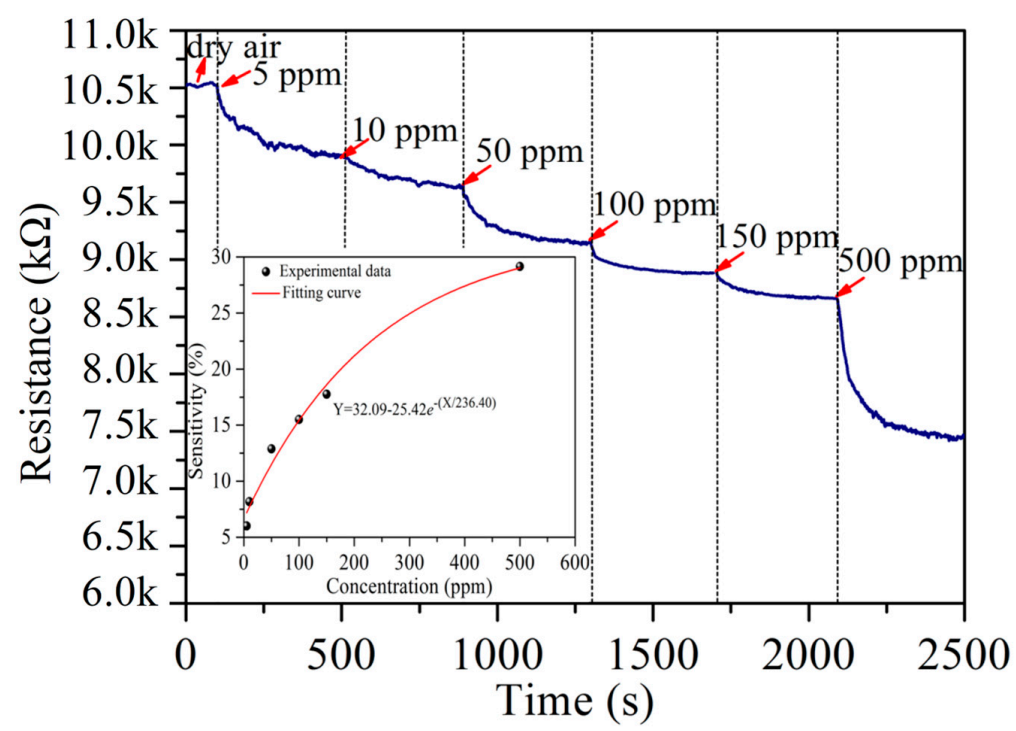

Figure 6. Resistance measurement of the $\mathrm{Ag}-\mathrm{SnO}_{2} / \mathrm{rGO}$ nanocomposite film sensor upon exposure to acetylene gas with cumulated concentrations at $90{ }^{\circ} \mathrm{C}$. 
Figure 7 shows the repeatability of the $\mathrm{Ag}-\mathrm{SnO}_{2} / \mathrm{rGO}$ film sensor with concentrations of 5, 150 and $500 \mathrm{ppm}$ acetylene at $90{ }^{\circ} \mathrm{C}$. There were no significant changes in sensor sensitivity during the repeated exposure/recovery cycles, indicating an acceptable repeatability for acetylene sensing. Figure 8 demonstrates the typical response and recovery curves of the $\mathrm{Ag}-\mathrm{SnO} / \mathrm{rGO}$ film sensor towards an acetylene pulse, at concentrations between 0 and 500 ppm, exhibiting good response/recovery behavior.

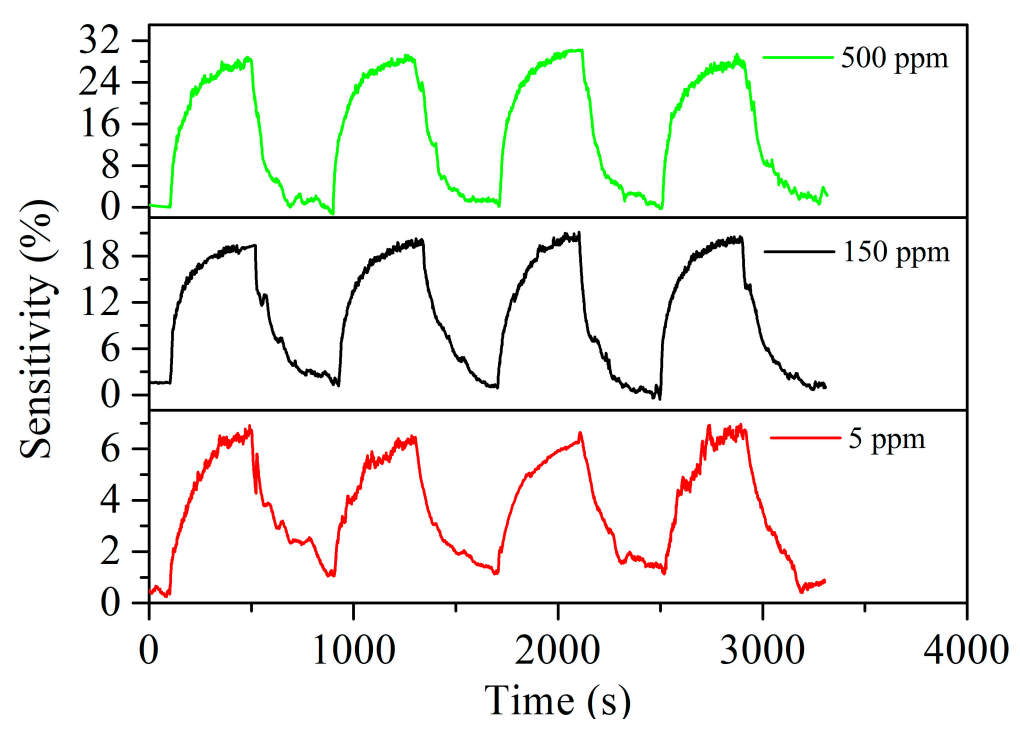

Figure 7. Repeatability of the $\mathrm{Ag}-\mathrm{SnO}_{2} / \mathrm{rGO}$ nanocomposite film sensor toward acetylene concentrations of 5,150 and $500 \mathrm{ppm}$ at $90^{\circ} \mathrm{C}$.

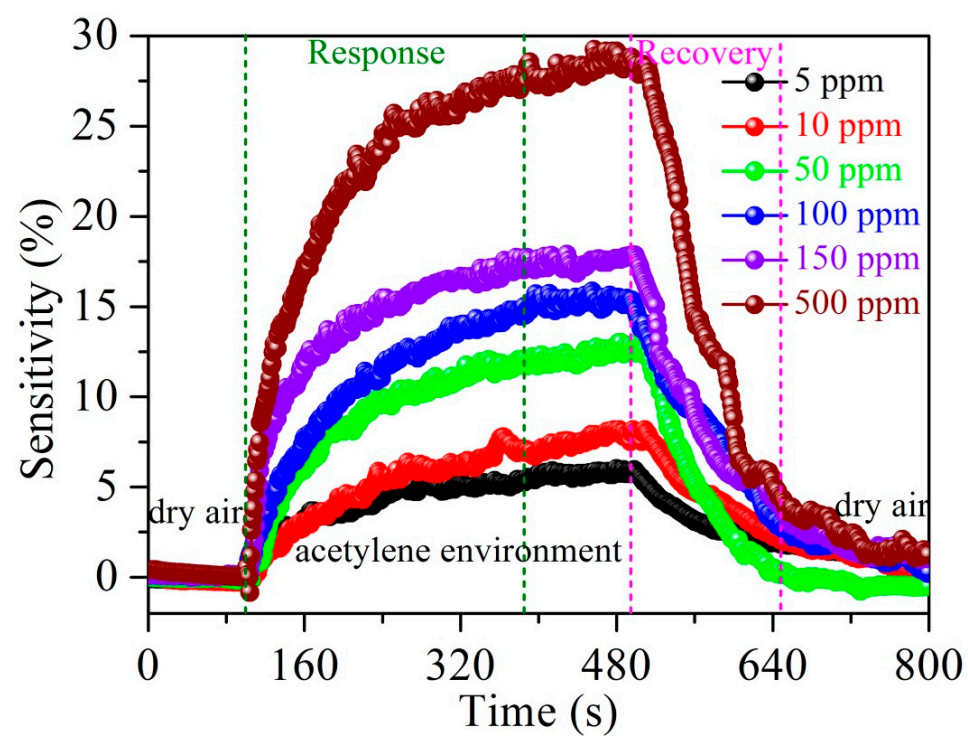

Figure 8. Typical response and recovery curves of the $\mathrm{Ag}-\mathrm{SnO}_{2} / \mathrm{rGO}$ nanocomposite film sensor to acetylene pulses between 0 and 500 ppm.

Figure 9 shows the response of the $\mathrm{Ag}-\mathrm{SnO}_{2} / \mathrm{rGO}$ nanocomposite film sensor to concentrations of 5, 150, and 500 ppm acetylene gas, measured every five days for over 30 days. It was clearly shown that the sensor response does not vary significantly with time, confirming that the $\mathrm{Ag}-\mathrm{SnO} / \mathrm{rGO}$ nanocomposite film sensor has good long-term stability. Figure 10 shows the experimental current-voltage (I-V) curves for the $\mathrm{SnO}_{2}, \mathrm{SnO}_{2} / \mathrm{rGO}$ and $\mathrm{Ag}-\mathrm{SnO}_{2} / \mathrm{rGO}$ film devices, measured by applying voltages from -4 to $4 \mathrm{~V}$. It is clearly shown that the measurement results indicate good Ohmic contact to n-type 
semiconductors for the three devices. A larger current passes through the $\mathrm{Ag}-\mathrm{SnO}_{2} / \mathrm{rGO}$ sensor than that of the $\mathrm{SnO}_{2} / \mathrm{rGO}$ and $\mathrm{SnO}_{2}$ sensors. This is because the doping of $\mathrm{Ag}$ and $\mathrm{rGO}$ results in a decrease in the resistance of the $\mathrm{Ag}-\mathrm{SnO}_{2} / \mathrm{rGO}$ film. Table 1 presents the performance of the proposed acetylene gas sensor in comparison with previous reported works $[12,13,15,23,36-38]$. The working temperature and responses for the prepared sensor are comparable to metal oxide-based sensors made by hydrothermal-RF magnetron sputtering, hydrothermal, electrospinning, spin-coating and sol-gel methods. The presented $\mathrm{Ag}-\mathrm{SnO}_{2} / \mathrm{rGO}$ film sensor exhibited a much higher response and a lower working temperature than that of its MOS-based counterparts.

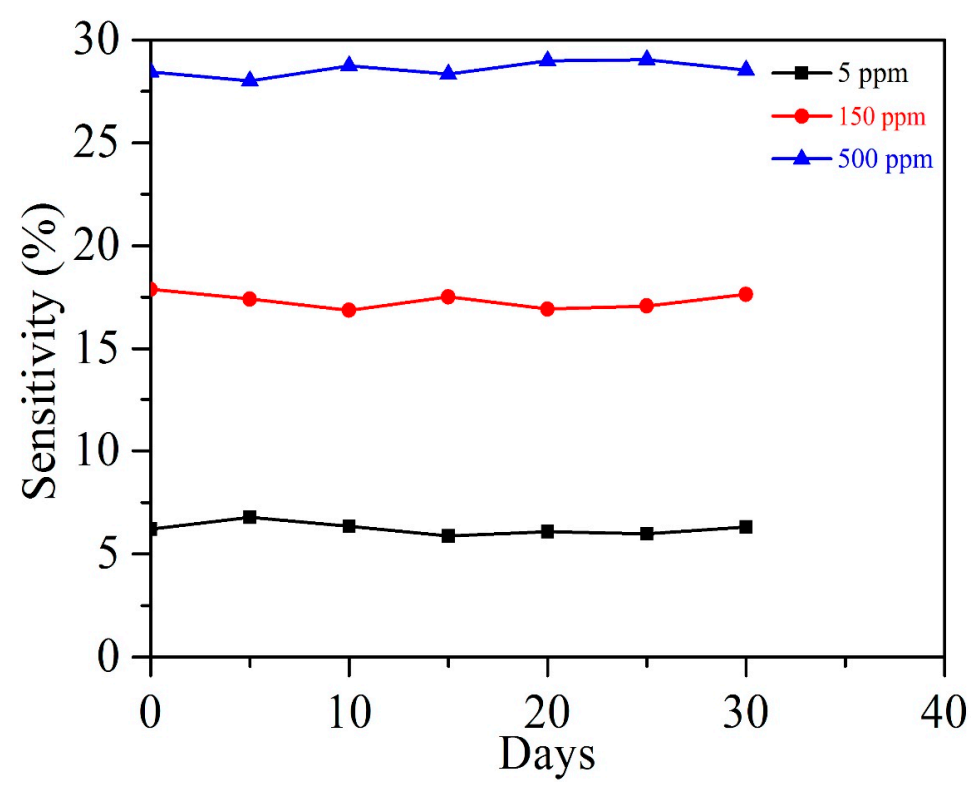

Figure 9. Long-term stability of the $\mathrm{Ag}-\mathrm{SnO}_{2} / \mathrm{rGO}$ nanocomposite film sensor, measured every five days for over 30 days.

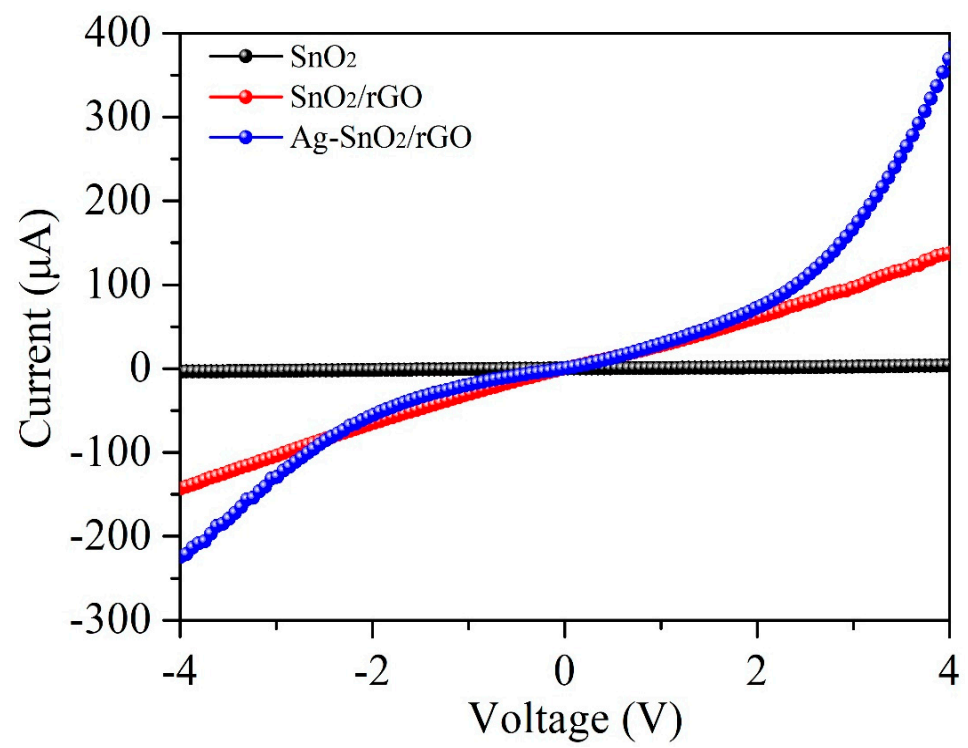

Figure 10. The measured I-V curves of the $\mathrm{SnO}_{2}, \mathrm{SnO}_{2} / \mathrm{rGO}$ and $\mathrm{Ag}-\mathrm{SnO}_{2} / \mathrm{rGO}$ films. 
Table 1. Performance of the presented sensor in this work compared with previous works.

\begin{tabular}{|c|c|c|c|c|}
\hline Sensing Material & Fabrication Method & Work Temperature & Response & Reference \\
\hline $\mathrm{Ag}-\mathrm{SnO}_{2} / \mathrm{rGO}$ & Layer-by-layer self-assembly & $90^{\circ} \mathrm{C}$ & $15.8 @ 100$ ppm & This paper \\
\hline $\mathrm{Ag}-\mathrm{ZnO}$ nanorods & $\begin{array}{l}\text { Hydrothermal-radio frequency } \\
\text { (RF) magnetron sputtering }\end{array}$ & $200^{\circ} \mathrm{C}$ & $27.2 @ 1000$ ppm & [12] \\
\hline Ag-hierarchical $\mathrm{ZnO}$ & Hydrothermal method & $200^{\circ} \mathrm{C}$ & $1.92 @ 1000$ ppm & [13] \\
\hline $\mathrm{NiO} / \mathrm{SnO}_{2}$ & Hydrothermal method & $206^{\circ} \mathrm{C}$ & $13.8 @ 100$ ppm & [15] \\
\hline $\mathrm{PdO}-\mathrm{SnO}_{2}$ & Hydrothermal method & $350^{\circ} \mathrm{C}$ & $7.22 @ 100$ ppm & [23] \\
\hline $\mathrm{Ni}-\mathrm{ZnO}$ & Electrospinning method & $250^{\circ} \mathrm{C}$ & $17 @ 2000$ ppm & [36] \\
\hline $\mathrm{SnO}_{2}$ & Spin-coating method & $300^{\circ} \mathrm{C}$ & $6.3 @ 10000$ ppm & [37] \\
\hline $\mathrm{Sm}_{2} \mathrm{O}_{3} / \mathrm{SnO}_{2}$ & Sol-gel method & $180^{\circ} \mathrm{C}$ & $63.8 @ 1000$ ppm & [38] \\
\hline
\end{tabular}

\subsection{Acetylene-Sensing Mechanism}

The $\mathrm{Ag}-\mathrm{SnO}_{2} / \mathrm{rGO}$ ternary nanocomposite film demonstrated excellent sensing properties towards acetylene gas at low temperatures. Its sensitive mechanism can be attributed to the synergistic effect of the ternary hybrids and the created potential barrier. Pristine $\mathrm{SnO}_{2}$ is an n-type semiconductor and electrons are majority carriers. Graphene, as one of the emerging 2D nanomaterials, has a unique layered structure, a large surface area-to-volume ratio and excellent electrical properties, which greatly facilitate the absorption and diffusion of acetylene gas molecules. Figure 11 shows the sensing mechanism of the $\mathrm{Ag}-\mathrm{SnO}_{2} / \mathrm{rGO}$ nanocomposite film in air and acetylene gas. The oxygen molecules adsorbed on the conduction band of n-type $\mathrm{SnO}_{2}$ are ionized to oxygen negative ions through the trapping of free electrons from the surface of the $\mathrm{SnO}_{2}$ [39]. When the sensor is exposed to acetylene gas, the adsorbed acetylene interacts with the oxygen's negative ions and produces carbon dioxide, water molecules and free electrons. The reaction is expressed as $\mathrm{C}_{2} \mathrm{H}_{2}$ (ads) $+\mathrm{O}^{-}$(ads) $\rightarrow \mathrm{CO}_{2}+\mathrm{H}_{2} \mathrm{O}+\mathrm{e}^{-}$, which leads to a decrease in the sensor's resistance $[14,28]$.

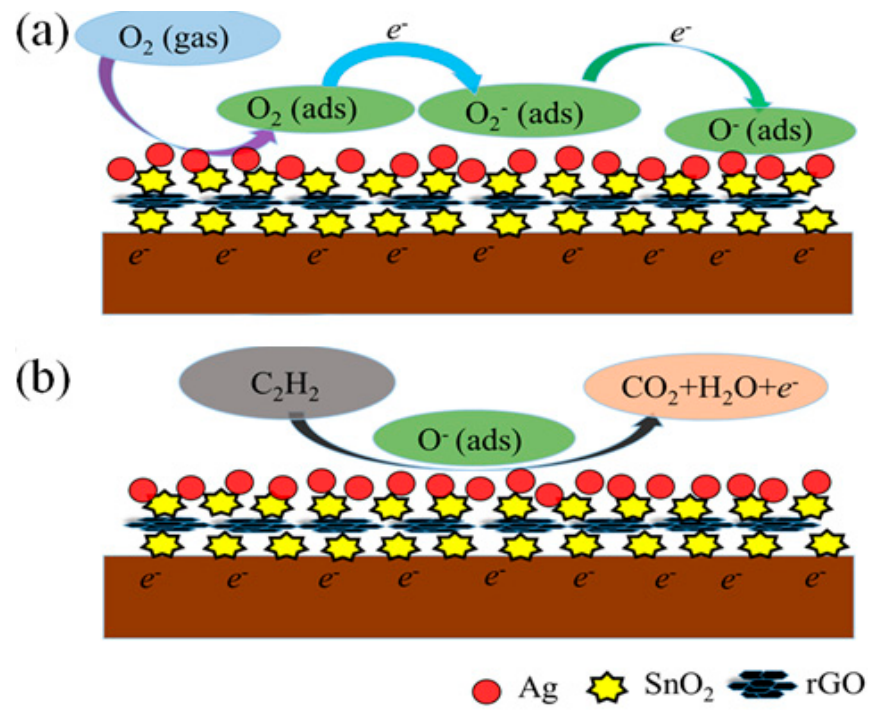

Figure 11. The sensing mechanism of the $\mathrm{Ag}-\mathrm{SnO}_{2} / \mathrm{rGO}$ nanocomposite film in (a) air and (b) acetylene gas.

The formation of a heterojunction at the interface between $\mathrm{rGO}$ and $\mathrm{SnO}_{2}$ is beneficial, because it enhances the acetylene-sensing properties. Figure 12a shows a schematic of an energy band diagram of the $\mathrm{SnO}_{2} / \mathrm{rGO}$ heterojunction. The band-gaps for n-type $\mathrm{SnO}_{2}$ and p-type $\mathrm{rGO}$ are 3.6 and $0.4 \mathrm{eV}$, respectively [34] and their work functions are 4.5 and $5.1 \mathrm{eV}$ for $\mathrm{SnO}_{2}$ and $\mathrm{rGO}$, respectively $[40,41]$. Because the Fermi energies are not at the same level and the rGO has a higher work function, when $\mathrm{SnO}_{2}$ and rGO come into contact with each other, electrons transfer from $\mathrm{SnO}_{2}$ to $\mathrm{rGO}$, and holes flow in the opposite direction until a dynamic equilibrium state is reached, and thus a depletion layer is formed at the interface [42]. Figure $12 \mathrm{~b}$ shows the variation of depletion layer thickness 
for the $\mathrm{SnO}_{2} / \mathrm{rGO}$ heterojunction. When the sensor was exposed to acetylene gas, the interaction between adsorbed $\mathrm{O}^{-}$and acetylene molecules released free electrons, with the released free electrons increasing the n-type doping of $\mathrm{SnO}_{2}$. Higher $\mathrm{SnO}_{2}$ doping results in a reduced depletion layer in $\mathrm{SnO}_{2}$, thereby decreasing the sensor resistance during acetylene gas exposure.
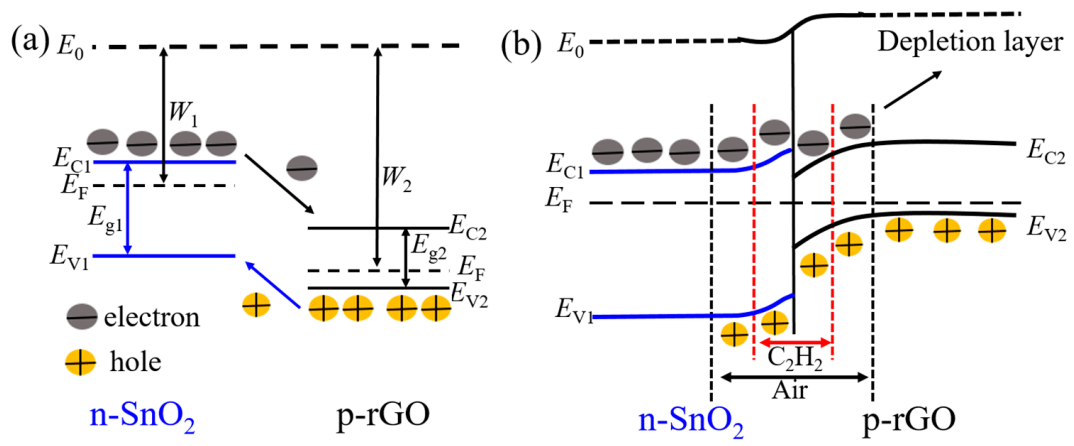

Figure 12. Schematic of the energy band diagram and the variation in depletion layer thickness for the $\mathrm{SnO}_{2} / \mathrm{rGO}$ heterojunction. ( $E_{\mathrm{C}}$, conductor band; $E_{\mathrm{g}}$, band gap; $E_{\mathrm{V}}$, valence band; $E_{\mathrm{F}}$, Fermi level; $\mathrm{W}$, work function)

The Ag NPs in the nanocomposite have a positive effect on electronic sensitization during gas adsorption [43,44]. A potential barrier can be created at the contact interface between $\mathrm{SnO}_{2}$ and $\mathrm{Ag}$, which is beneficial to the enhancement of gas-sensing. Electrons transfer from $\mathrm{SnO}_{2}$ to $\mathrm{Ag} \mathrm{NPs}$ and form a highly-resistive "barrier layer" in air, and Ag NPs become centers for electron accumulation. When the sensor is exposed to acetylene gas, electrons transfer from acetylene gas to the Ag NPs and then to $\mathrm{SnO}_{2}$; the highly-resistive "barrier layer" is transformed into a highly-conductive "anti-barrier layer", which improves the electron mobility and sensing performance of the $\mathrm{Ag}-\mathrm{SnO}_{2} / \mathrm{rGO}$ nanocomposite sensor.

\section{Conclusions}

In this work, an acetylene gas sensor, based on $\mathrm{Ag}-\mathrm{SnO}_{2} / \mathrm{rGO}$ nanocomposite film was fabricated by layer-by-layer self-assembly technology. Successful preparation of the $\mathrm{Ag}-\mathrm{SnO}_{2} / \mathrm{rGO}$ nanocomposite was characterized and confirmed by means of SEM, TEM, XRD and Raman spectrum. The $\mathrm{Ag}-\mathrm{SnO}_{2} / \mathrm{rGO}$ nanocomposite sensor exhibited excellent sensing behaviors towards acetylene in terms of response, repeatability, stability and response/recovery characteristics at an optimal temperature of $90^{\circ} \mathrm{C}$, which are superior to pure $\mathrm{SnO}_{2}$ and $\mathrm{SnO}_{2} / \mathrm{rGO}$ film sensors. The underlying sensing mechanism of the $\mathrm{Ag}-\mathrm{SnO}_{2} / \mathrm{rGO}$ sensor was explored. This work provides guidance for an acetylene sensor based on $\mathrm{Ag}-\mathrm{SnO}_{2} / \mathrm{rGO}$ ternary nanocomposites.

Acknowledgments: This work was supported by the National Natural Science Foundation of China (Grant No. 51777215, 51407200, 51403180), the Fundamental Research Funds for the Central Universities of China (Grant No. 15CX05041A), the Science and Technology Development Plan Project of Qingdao (Grant No. 16-6-2-53-nsh), the Science Foundation for Distinguished Young Scholars by Xinjiang Science and Technology Department (2014711010), the Xinjiang Recruitment Program of High-level Innovative Talents (2015RST011712), and the Science Foundation for Young Teachers by Xinjiang Education Department (XJEDU2014S075).

Author Contributions: Dongzhi Zhang supervised this work and wrote the article; Chuanxing Jiang and Nailiang Yin performed the experiment and analyzed the data; Yao Yao, Talgar Shaymurat and Xiaoyan Zhou analyzed part of the sensing mechanism.

Conflicts of Interest: The authors declared that they have no conflict of interest to this work.

\section{References}

1. Antonsson, A.-B.; Christensson, B.; Berge, J.; Sjögren, B. Fatal carbon monoxide intoxication after acetylene gas welding of pipes. Ann. Occup. Hyg. 2013, 57, 662-666. [PubMed] 
2. Steinmetz, J.; Lee, H.-J.; Kwon, S.; Lee, D.-S.; Goze-Bac, C.; Abou-Hamad, E.; Kim, H.; Park, Y.W. Routes to the synthesis of carbon nanotube-polyacetylene composites by Ziegler-Natta polymerization of acetylene inside carbon nanotubes. Curr. Appl. Phys. 2007, 7, 39-41. [CrossRef]

3. Saroha, R.; Panwar, A.K. Effect of in situ pyrolysis of acetylene $\left(\mathrm{C}_{2} \mathrm{H}_{2}\right)$ gas as a carbon source on the electrochemical performance of $\mathrm{LiFePO}_{4}$ for rechargeable lithium-ion batteries. J. Phys. D Appl. Phys. 2017, 50, 255501. [CrossRef]

4. Bastos, D.C.; Dos Santos, A.E.F.; Simao, R.A. Acetylene coating on cornstarch plastics produced by cold plasma technology. Starch-Stärke 2014, 66, 267-273. [CrossRef]

5. Jin, L.; Chen, W.; Zhang, H.; Xiao, G.; Yu, C.; Zhou, Q. Characterization of reduced greaphene oxide (rGO)-loaded $\mathrm{SnO}_{2}$ nanocomposite and applications in $\mathrm{C}_{2} \mathrm{H}_{2}$ gas detection. Appl. Sci. 2017, 7, 19. [CrossRef]

6. Wan, F.; Zhou, Q.; Zou, J.; Gu, Z.; Chen, W.; Wang, C. Using a sensitive optical system to analyze gases dissolved in samples extracted from transformer oil. IEEE Electr. Insul. Mag. 2014, 30, 15-22. [CrossRef]

7. Chen, W.; Liu, B.; Zhou, H.; Wang, Y.; Wang, C. Diode laser-based photoacoustic spectroscopy detection of acetylene gas and its quantitative analysis. Eur. Trans. Electr. Power 2012, 22, 226-234. [CrossRef]

8. Yan, G.; Zhang, A.P.; Ma, G.; Wang, B.; Kim, B.; Im, J.; He, S.; Chung, Y. Fiber-optic acetylene gas sensor based on microstructured optical fiber bragg gratings. IEEE Photonic Technol. Lett. 2011, 23, 1588-1590. [CrossRef]

9. Zhou, Q.; Liu, H.; Hong, C.; Xu, L.; Chen, W. Fabrication and enhanced acetylene sensing properties of PdO-decorated $\mathrm{SnO}_{2}$ composites chemical sensor. Sens. Lett. 2016, 14, 1144-1149. [CrossRef]

10. Li, C.L.; Su, Y.; Lv, X.Y.; Xia, H.L.; Wang, Y.J. Electrochemical acetylene sensor based on Au/MWCNTs. Sens. Actuators B Chem. 2010, 149, 427-431. [CrossRef]

11. Zhou, Q.; Cao, M.; Li, W.; Tang, C.; Zhu, S. Research on acetylene sensing properties and mechanism of $\mathrm{SnO}_{2}$ based chemical gas sensor decorated with $\mathrm{Sm}_{2} \mathrm{O}_{3}$. J. Nanosci. Nanotechnol. 2015, 2015, 714072.

12. Uddin, A.S.M.I.; Yaqoob, U.; Phan, D.-T.; Chung, G.-S. A novel flexible acetylene gas sensor based on PI/PTFE-supported Ag-loaded vertical ZnO nanorods array. Sens. Actuators B Chem. 2016, 222, 536-543. [CrossRef]

13. Lee, K.-W.; Phan, D.-T.; Chung, G.-S. Fabrication of low-temperature acetylene gas sensor based on Ag nanoparticles loaded hierarchical $\mathrm{ZnO}$ nanostructures. Electron. Lett. 2015, 51, 572-574. [CrossRef]

14. Uddin, A.S.M.I.; Phan, D.-T.; Chung, G.-S. Low temperature acetylene gas sensor based on Ag nanoparticles-loaded ZnO-reduced graphene oxide hybrid. Sens. Actuators B Chem. 2015, 207, 362-369. [CrossRef]

15. Lin, Y.; Li, C.; Wei, W.; Li, Y.; Wen, S.; Sun, D.; Chen, Y.; Ruan, S. A new type of acetylene gas sensor based on a hollow heterostructure. RSC Adv. 2015, 5, 61521-61527. [CrossRef]

16. Akash, K.; Sun-Woo, C.; Hyoun, W.K.; Sang, S.K. Highly sensitive and selective $\mathrm{H}_{2}$ sensing by $\mathrm{ZnO}$ nanofibers and the underlying sensing mechanism. J. Hazard. Mater. 2015, 286, 229-235.

17. Rawal, I. Facial synthesis of hexagonal metal oxide nanoparticles for low temperature ammonia gas sensing applications. RSC Adv. 2015, 5, 4135-4142. [CrossRef]

18. Miller, D.R.; Akbar, S.A.; Morris, P.A. Nanoscale metal oxide-based heterojunctions for gas sensing: A review. Sens. Actuators B Chem. 2014, 204, 250-272. [CrossRef]

19. Shim, Y.S.; Kim, D.H.; Jeong, H.Y.; Kim, Y.H.; Nahm, S.H.; Kang, C.Y.; Kim, J.S.; Lee, W.; Jang, H.W. Utilization of both-side metal decoration in close-packed $\mathrm{SnO}_{2}$ nanodome arrays for ultrasensitive gas sensing. Sens. Actuators B Chem. 2015, 213, 314-321. [CrossRef]

20. Zhang, Z.J.; Kaneti, Y.V.; Jiang, X.C.; Yu, A.B. Hydrothermal synthesis of sodium vanadium oxide nanorods for gas sensing application. Sens. Actuators B Chem. 2014, 202, 803-809. [CrossRef]

21. Zhang, L.; Zhao, J.; Zheng, J.; Li, L.; Zhu, Z. Hydrothermal synthesis of hierarchical nanoparticle-decorated $\mathrm{ZnO}$ microdisks and the structure-enhanced acetylene sensing properties at high temperatures. Sens. Actuators B Chem. 2014, 158, 144-150. [CrossRef]

22. Tamaekong, N.; Liewhiran, C.; Wisitsoraat, A.; Phanichphant, S. Acetylene sensor based on Pt/ZnO thick films as prepared by flame spray pyrolysis. Sens. Actuators B Chem. 2011, 152, 155-161. [CrossRef]

23. Chen, W.; Zhou, Q.; Gao, T.; Su, X.; Wan, F. Pd-doped $\mathrm{SnO}_{2}$-based sensor detecting characteristic fault hydrocarbon gases in transformer oil. J. Nanomater. 2013, 2013, 127345. [CrossRef]

24. Uddin, A.S.M.I.; Lee, K.-W.; Chung, G.-S. Acetylene gas sensing properties of an Ag-loaded hierarchical $\mathrm{ZnO}$ nanostructure-decorated reduced graphene oxide hybrid. Sens. Actuators B Chem. 2015, 216, 33-40. [CrossRef] 
25. Zhang, D.; Liu, J.; Xia, B. Quantitative detection of formaldehyde and ammonia gas via metal oxide-modified graphene-based sensor array combining with neural network model. Sens. Actuators B Chem. 2017, 240, 55-65. [CrossRef]

26. Alzari, V.; Sanna, V.; Biccai, S.; Caruso, T.; Politano, A.; Scaramuzza, N.; Sechi, M.; Nuvoli, D.; Sanna, R.; Mariani, A. Tailoring the physical properties of nanocomposite films by the insertion of graphene and other nanoparticles. Compos. Part B Eng. 2014, 60, 29-35. [CrossRef]

27. Gugliuzza, A.; Politano, A.; Drioli, E. The advent of graphene and other two-dimensional materials in membrane science and technology. Curr. Opin. Chem. Eng. 2017, 16, 78-85. [CrossRef]

28. Uddin, A.S.M.I.; Chung, G.-S. Synthesis of highly dispersed $\mathrm{ZnO}$ nanoparticles on graphene surface and their acetylene sensing properties. Sens. Actuators B Chem. 2014, 205, 338-344. [CrossRef]

29. Zhang, D.; Yin, N.; Xia, B. Facile fabrication of ZnO nanocrystalline-modified graphene hybrid nanocomposite toward methane gas sensing application. J. Mater. Sci.-Mater. Electron. 2015, 26, 5937-5945. [CrossRef]

30. Zhang, D.; Jiang, C.; Liu, J.; Cao, Y. Carbon monoxide gas sensing at room temperature using copper oxide-decorated graphene hybrid nanocomposite prepared by layer-by-layer self-assembly. Sens. Actuators B Chem. 2017, 247, 875-882. [CrossRef]

31. Zhang, D.; Liu, J.; Jiang, C.; Li, P.; Sun, Y. High-performance sulfur dioxide sensing properties of layer-by-layer self-assembled titania-modified graphene hybrid nanocomposite. Sens. Actuators B Chem. 2017, 245, 560-567. [CrossRef]

32. Bai, S.L.; Liu, J.C.; Guo, J.; Luo, R.X.; Li, D.Q.; Song, Y.J.; Liu, C.C.; Chen, A.F. Facile preparation of $\mathrm{SnO}_{2} / \mathrm{NiO}$ composites and enhancement of sensing performance to $\mathrm{NO}_{2}$. Sens. Actuators B Chem. 2017, 249, $22-29$.

33. Ding, C.; Ma, Y.; Lai, X.; Yang, Q.; Xue, P.; Hu, F.; Geng, W. Mesoporous $\mathrm{Ag} / \mathrm{In}_{2} \mathrm{O}_{3}$ composite derived from indium organic framework as high performance formaldehyde sensor. J. Solid State Chem. 2017, 251, 170-175.

34. Zhang, D.; Liu, J.; Xia, B. Nitrogen dioxide-sensing properties at room temperature of metal oxide-modified graphene composite via one-step hydrothermal method. J. Electron. Mater. 2016, 45, 4324-4330. [CrossRef]

35. Zhang, D.; Liu, J.; Chang, H.; Liu, A.; Xia, B. Characterization of a hybrid composite of $\mathrm{SnO}_{2}$ nanocrystal-decorated reduced graphene oxide for ppm-level ethanol gas sensing application. RSC Adv. 2015, 5, 18666-18672. [CrossRef]

36. Zhang, D.; Chang, H.; Li, P.; Liu, R.; Xue, Q. Fabrication and characterization of an ultra-sensitive humidity sensor based on metal oxide/graphene hybrid nanocomposite. Sens. Actuators B Chem. 2016, 225, 233-240. [CrossRef]

37. Wang, X.; Zhao, M.; Liu, F.; Jia, J.; Li, X.; Cao, L. $\mathrm{C}_{2} \mathrm{H}_{2}$ gas sensor based on Ni-doped ZnO electrospun nanofibers. Ceram. Int. 2013, 39, 2883-2887. [CrossRef]

38. Liewhiran, C.; Tamaekong, N.; Wisitsoraat, A.; Phanichphant, S. Highly selective environmental sensors based on flame-spray-made $\mathrm{SnO}_{2}$ nanoparticles. Sens. Actuators B Chem. 2012, 163, 51-60. [CrossRef]

39. Qi, Q.; Zhang, T.; Zheng, X.; Fan, H.; Liu, L.; Wang, R.; Zeng, Y. Electrical response of $\mathrm{Sm}_{2} \mathrm{O}_{3}$-doped $\mathrm{SnO}_{2}$ to $\mathrm{C}_{2} \mathrm{H}_{2}$ and effect of humidity interference. Sens. Actuators B Chem. 2008, 134, 36-42. [CrossRef]

40. Zhang, D.; Sun, Y.; Jiang, C.; Zhang, Y. Room temperature hydrogen gas sensor based on palladium decorated tin oxide/molybdenum disulfide ternary hybrid via hydrothermal route. Sens. Actuators B 2017, 242, $15-24$. [CrossRef]

41. Yang, H.; Li, J.; Yu, D.; Li, L. Seed/catalyst free growth and self-powered photoresponse of vertically aligned $\mathrm{ZnO}$ nanorods on reduced graphene oxide nanosheets. Cryst. Growth Des. 2016, 16, 4831-4838. [CrossRef]

42. Di Bartolomeo, A. Graphene schottky diodes: An experimental review of the rectifying graphene/semiconductor heterojunction. Phys. Rep. 2016, 606, 1-58. [CrossRef]

43. Kwon, Y.; Kim, H.; Lee, S.; Chin, I.J.; Seong, T.Y.; Lee, W.I.; Lee, C. Enhanced ethanol sensing properties of $\mathrm{TiO}_{2}$ nanotube sensors. Sens. Actuators B Chem. 2012, 173, 441-446. [CrossRef]

44. Zhang, D.; Sun, Y.; Jiang, C.; Yao, Y.; Wang, D.; Zhang, Y. Room-temperature highly sensitive CO gas sensor based on Ag-loaded zinc oxide/molybdenum disulfide ternary nanocomposite and its sensing properties. Sens. Actuators B Chem. 2017, 253, 1120-1128. [CrossRef]

(C) 2017 by the authors. Licensee MDPI, Basel, Switzerland. This article is an open access article distributed under the terms and conditions of the Creative Commons Attribution (CC BY) license (http:/ / creativecommons.org/licenses/by/4.0/). 